\title{
Uji Kinerja Modul Pelatihan Motor Penunjang Mata Kuliah Mekatronika
}

\author{
Anwar Mujadin $^{1}$, Dwi Astharini² \\ 1,2 Program Studi Teknik Elektro, Fakultas Sains dan Teknologi, , Universitas Al Azhar Indonesia, \\ Kompleks Masjid Agung Al Azhar, Kebayoran Baru Jakarta Selatan, Kode Pos 12110 \\ Penulis untuk Korespondensi/E-mail: amujadin@uai.ac.id
}

\begin{abstract}
Abstrak - Teknis pemberian pulse width modulation (PWM) menjadi sangat penting terutama dalam pengendalian motor seperti pada motor direct current (motror DC), motor stepper maupun motor servo. Lebar pulsa duty cycle dalam satu perioda waktu PWM akan menentukan tingkat keakuratan kecepatan maupun sudut. PWM diatur memggunakan program (assembly), kemudian kecepatanya diamati menggunakan alat ukur laser tachometer sedangkan tingkat kepersisian sudutnya diukur menggunakan pola kertas (template). Untuk mendapatkan performa independensi setiap motor, maka motor dikendalikan dan diujicobakan tanpa menggunakan beban (tidak ada uji torsi).
\end{abstract}

Kata kunci-pulse width modulation mekatronika motor traineer.

Abstract - the pulse width modulation (PWM) is especially inportant for motor controlling such as in DC motor, stepper motor and servo motor. The width of duty cycle in time period will determine speed and angle accurately. PWM wil be generated by using low level programm code of microcontroller (assembler), then speed of motor observed by laser tachometer and angle rotation observed by paper patern template. To get the performance independence of each motor, the motor is controlled and tested without the use of loads (no test of torque).

Keywords - pulse width modulation motor traineer for mechatronic modules.

\section{PENDAHULUAN}

$\mathrm{D}$ alam kehidupan sehari hari kita bisa menemukan banyak perangkat elektronika yang menerapkan sistem mekatronika. Sesuai sifatnya, mekatronika adalah suatu disiplin ilmu teknik yang mengkombinasikan sinergi dari teknik mesin dan elektronika. Keterkaitan disiplin ilmu yang terlibat dalam mekatronika tersebut diatas adalah teknik mesin dengan teknik elektro menghasilkan elektro mekanik, teknik mesin dengan teknik komputer menghasilkan software mesin dan teknik elektro dengan teknik komputer menghasilkan software elektro. Semua produk-produk modern saat ini yang ada dipasaran dibuat dengan latar belakang dari disiplin ilmu tersebut diatas.
Penerapan ilmu mekatronika saat ini adalah berupa divais embedded yang memiliki kemampuan spesifik untuk mempermudah kinerja manusia dijaman modern ini. Mesin cuci, mesin computer numerical control (CNC), robot industri, wahana arena permainan Ancol, dan lain sebagainya adalah teknologi yang tergolong sistem mechatronic embedded systems. Mekatronik embedded system adalah suatu sitem yang tertanam dalam suatu perangkat yang didesain untuk suatu perangkat tertentu dengan kemampuan yang spesifik. Mekatronika dikategorikan oleh majalah Technology Review pada tahun 2003 sebagai sepuluh teknologi yang dalam waktu dekat dapat mengubah hidup manusia [1].

Mata kuliah mekatronika dosen mengajarkan kepada mahasiswanya pada sistem kendali mekanik penggerak (aktuator) seperti motor dc, 
motor servo, dan motor stepper, dilanjutkan dengan mengajarkan sensor sebagai masukan aktuator yang berbasis digital maupun analog seperti sensor optik, switch, suhu, magnet dan lain sebagainya. Implementasi mata kuliah mekatronik harus spesifik, tepat sasaran tentunya dengan cost yang cukup murah.

Penulis telah berhasil merancang bangun sebuah prototipe modul pelatihan penunjang mata kuliah mekatronika berbasis mikrokontroller Arduino uno R3 terintegrasi dalam satu paket modul dibuat dari komponen lokal dengan disain murah, mudah dirawat, dan mudah diperbaiki.

Pada tulisan ini akan dibahas mengenai pemberian pulse wide modulation (PWM) terutama dalam pengendalian motor DC, motor stepper maupun motor servo. Parameter yang diukur adalah kepersisian sudut dan kecepatan rotasi. motor dikendalikan dan diujicobakan tanpa menggunakan beban (tidak ada uji torsi).

\section{TINJAUAN PUSTAKA}

\section{Motor DC}

Motor DC banyak digunakan sebagai penggerak dalam berbagai peralatan mekatronik. Motor DC berputar sebagai hasil saling interaksi dua medan magnet. Interaksi ini terjadi disebabkan arus yang mengalir pada kumparan. Elemen utama motor DC adalah: magnet, armatur atau rotor, commutator sikat (brushes) dan as poros (axle). Pada Gambar 1 diperlihatkan elemen utama motor DC [2].

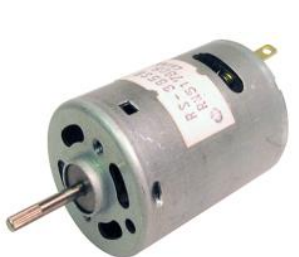

(a)

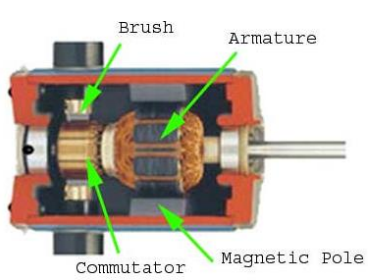

(b)
Gambar 1. Elemen motor DC [2].

Metode pulse width modulation (PWM) adalah metode yang cukup efektif untuk mengendalikan kecepatan motor DC. PWM ini bekerja dengan cara membuat gelombang persegi yang memiliki perbandingan pulsa high terhadap pulsa low yang di-set tertentu, biasanya diskalakan dari 0 hingga $100 \%$. Perbandingan pulsa high terhadap pulsa low
PWM dinamakan dengan duty cycle. Perbandingan pulsa high terhadap low ini akan menentukan jumlah daya yang diberikan ke motor DC. Pada Gambar 2 diperlihatkan beberapa duty cycle PWM pada pengendalian motor DC

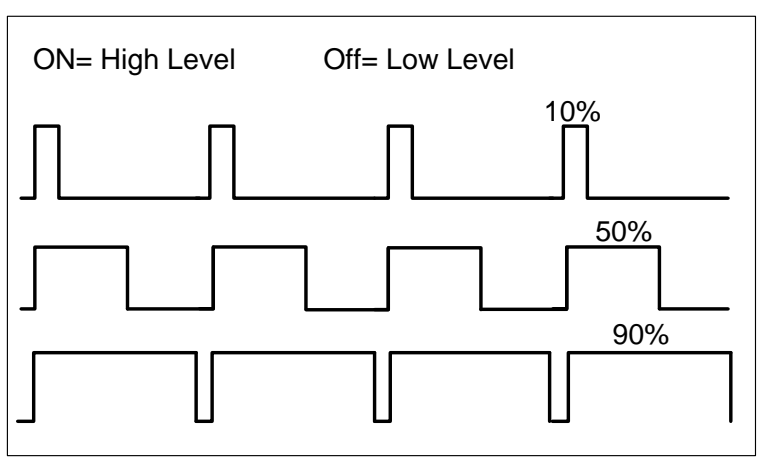

Gambar 2. Duty cycle PWM pengendalian motor DC [2]

Apabila diinginkan motor DC dapat bergerak 2 arah, maka diperlukan rangkaian H-Bridge. Rangkaian yang paling sederhana adalah menggunakan IC H-Bridge BJT Darlinton L298. IC H-bridge ini mampu mengendalikan dua motor DC hingga arus 2A (heatsink). Pada Gambar 3 diperlihatkan rangkaian pengendali motor DC (2 arah) menggunakan H-Bridge L298 [3].

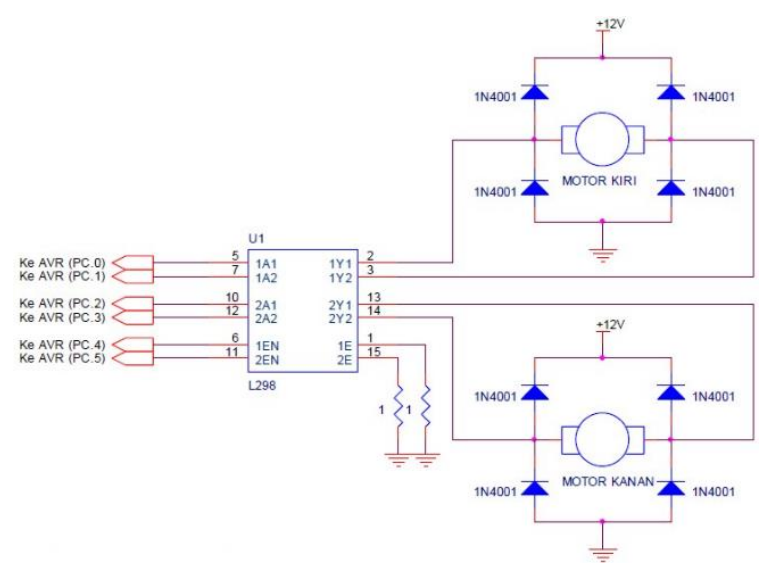

Gambar 3. Pengendalian dua motor DC menggunakan H bridge L298 [3].

\section{Motor Stepper}

Motor stepper adalah motor DC yang gerakannya bertahap (step per step) dan memiliki akurasi yang tinggi tergantung pada spesifikasinya. Setiap motor stepper mampu berputar untuk setiap stepnya dalam satuan sudut $(0.75,0.9,1.8)$, makin kecil sudut per 
step-nya maka gerakan motor stepper tersebut makin presisi. Pada Gambar 4 diperlihatkan motor stepper tipe hibrid berikut penampang melintang dari motor stepper tersebut [4].
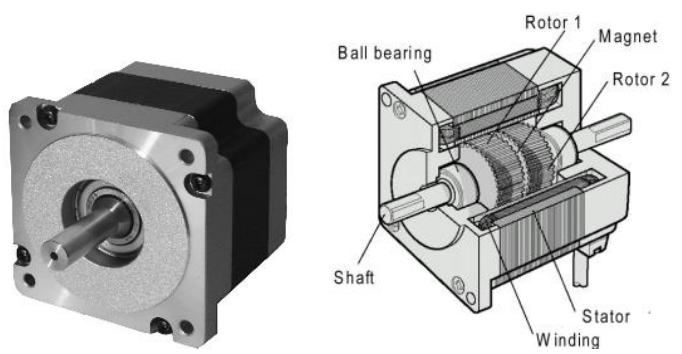

Gambar 4. Motor stepper tipe hibrid a) gambar nyata b)Penampang melintang motor stepper [4]

Motor stepper merupakan motor DC yang tidak memiliki komutator. Pada umumnya motor stepper hanya mempunyai kumparan pada statornya sedangkan pada bagian rotornya merupakan magnet permanent. Dengan model motor seperti ini maka motor stepper dapat diatur posisinya pada posisi tertentu ke arah yang diinginkan, searah jarum jam atau sebaliknya.

Kecepatan motor stepper pada dasarnya ditentukan oleh kecepatan pemberian data pada komutatornya. Semakin cepat data yang diberikan maka motor stepper akan semakin cepat pula berputarnya. Untuk mengatur gerakan motor per step-nya dapat dilakukan dengan dua cara berdasarkan simpangan sudut gerakannya yaitu full step dan half step. Pada Tabel 1 diperlihatkan bit data motor stepper untuk jenis putaran dan step [4].

Tabel 1. Bit data motor stepper untuk jenis putaran dan jenis langkah (step) [4][7]

\begin{tabular}{|c|c|c|c|c|c|c|c|c|c|c|c|}
\hline \multicolumn{6}{|c|}{ FULL STEP } & \multicolumn{6}{|c|}{ HALF STEP } \\
\hline Step & Pulse & S3 & S2 & S1 & S0 & Step & Pulse & S3 & S2 & S1 & S0 \\
\hline \multirow{5}{*}{ KIRI } & 1 & 0 & 0 & 0 & 1 & \multirow{8}{*}{ KIRI } & 1 & 0 & 0 & 0 & 1 \\
\hline & 2 & 0 & 0 & 1 & 0 & & 2 & 0 & 0 & 1 & 1 \\
\hline & 3 & 0 & 1 & 0 & 0 & & 3 & 0 & 0 & 1 & 0 \\
\hline & 4 & 1 & 0 & 0 & 0 & & 4 & 0 & 1 & 1 & 0 \\
\hline & & & & & & & 5 & 0 & 1 & 0 & 0 \\
\hline \multirow{4}{*}{ KANAN } & 1 & 1 & 0 & 0 & 0 & & 6 & 1 & 1 & 0 & 0 \\
\hline & 2 & 0 & 1 & 0 & 0 & & 7 & 1 & 0 & 0 & 0 \\
\hline & 3 & 0 & 0 & 1 & 0 & & 8 & 1 & 0 & 0 & 1 \\
\hline & 4 & 0 & 0 & 0 & 1 & & & & & & \\
\hline
\end{tabular}

Pada Gambar 5 diperlihatkan posisi rotor pada saat komutatornya diberi pulsa full step dan pada Gambar 6 diperlihatkan posisi rotor pada saat komutatornya diberi pulsa half step.

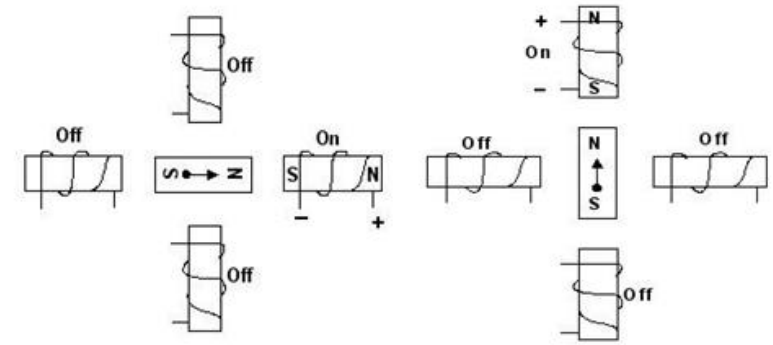

Gambar 5. Posisi rotor bila diberi pulsa full step.

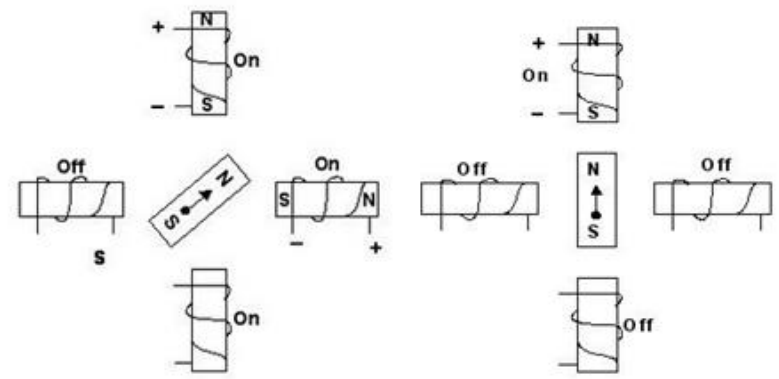

Gambar 6. Posisi rotor bila diberi pulsa half step

\section{Motor Servo}

Motor servo adalah sebuah motor dengan sistem closed feedback di mana posisi dari motor akan diinformasikan kembali ke rangkaian kontrol yang ada di dalam motor servo. Motor servo terdiri dari susunan motor DC, gear, potensiometer dan rangkaian kontrol, seperti yang diperlihatkan pada Gambar 7 dibawah ini [5].

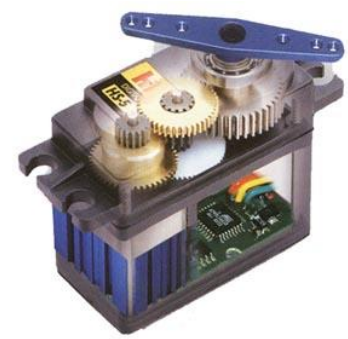

Gambar 7. Susunan komponen motor servo [5].

Sudut dari sumbu motor servo diatur berdasarkan lebar pulsa yang dikirim melalui kaki sinyal dari kabel motor. Motor servo biasanya hanya bergerak mencapai sudut tertentu saja dan tidak kontinyu. Walau demikian, untuk beberapa keperluan tertentu, motor servo dapat dimodifikasi agar bergerak kontinyu Motor servo adalah motor yang mampu bekerja dua arah dimana arah dan sudut pergerakan rotornya dapat dikendalikan hanya 
dengan memberikan pengaturan duty cycle sinyal pulse width modulation (PWM) pada bagian pin kontrolnya. Sinyal PWM terdiri dari tiga lebar pulsa yaitu $1 \mathrm{~ms}, 1.5 \mathrm{~ms}$ dan $2 \mathrm{~ms}$ dalam perioda konstan $20 \mathrm{~ms}$ seperti yang diperlihatkan pada Gambar 8 berikut.

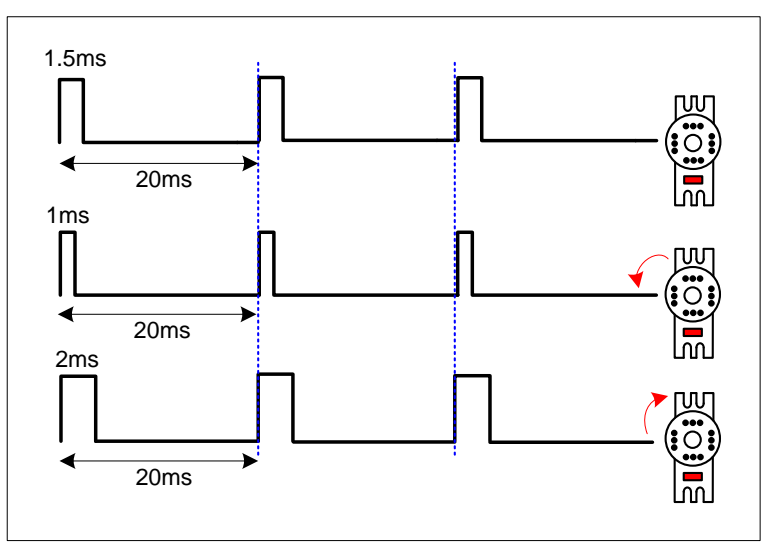

Gambar 8. Sinyal PWM pada servo motor [5].

Motor servo terdiri dari 2 jenis yaitu :

a. Motor Servo Standar $180^{\circ}$, motor servo jenis ini hanya mampu bergerak dua arah (CW dan $\mathrm{CCW}$ ) dengan defleksi masingmasing sudut mencapai $90^{\circ}$ sehingga total defleksi sudut dari kanan - tengah - kiri adalah $180^{\circ}$.

b. Motor servo continuous, motor servo jenis ini mampu bergerak dua arah $(\mathrm{CW}$ dan CCW) tanpa batasan defleksi sudut putar (dapat berputar secara kontinyu) [8][9].

\section{METODE PENELITIAN}

Kerangka fikir dari metode penilitian:

a. Uji program menggunakan emulasi proteus 8 .

b.Uji sudut menggunakan kertas pola (tempalate) dalam prototip.

c. Mencari korelasi waktu duty cycle terhadap kecepatan rotasi.

d.Mencari korelasi waktu duty cycle terhadap kepersisian sudut.

e.Mencari sudut simpangan terhadap perubahan sudut putar.

\section{HASIL DAN PEMBAHASAN}

Code program Mikrokontroller Arduino Uno R3 sebelumnya di emulasikan pada perangkat lunak Proteus [6]. Pulsa PWM yang dibangkitkan oleh mikrokontroler kemudian selanjutnya di-trace pada perangkat lunak ini. Pada gambar 9 diperlihatkan wiring diagram Proteus pada pengendalian motor

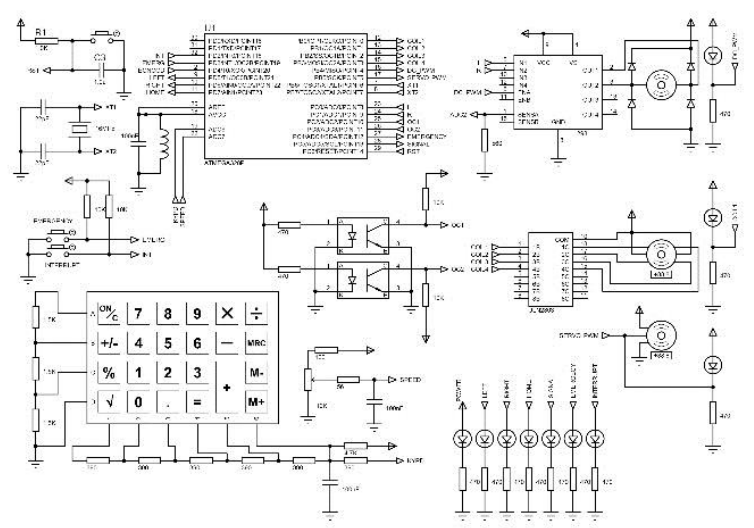

Gambar 9. Wiring diagram Proteus pengendalian motor

Prototipe dilengkapi dengan kertas pola (template) untuk mengukur kepersisian sudut rotasi dari semua motor uji. Pada pengujian motor servo dan motor stepper dilengkapi dengan optocoupler untuk menentukan sudut homing (0 derajat). Pada Gambar 10 diperlihatkan kertas pola (template) pengukur kepersisian sudut.

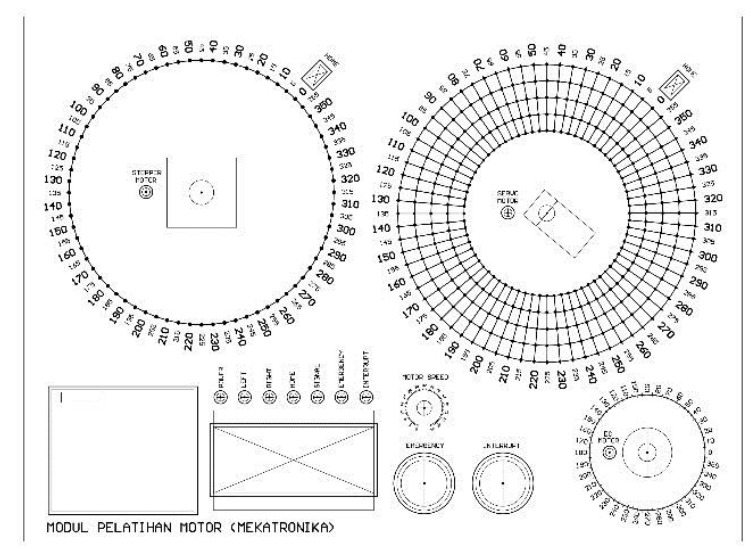

Gambar 10. Kertas Pola (template) pengukur kepersisian sudut 


\section{Pengujian Motor DC}

Pada tabel 2 diperlihatkan hasil pengujian motor DC perubahan duty cycle terhadap perubahan RPM (PWM kontinyu).

Tabel 2. Perubahan duty cycle terhadap perubahan RPM pada motor DC(PWM kontinyu)

\begin{tabular}{|c|c|c|c|c|}
\hline \multicolumn{4}{|c|}{ Motor DC } & \\
\hline \multicolumn{2}{|c|}{ Pulse } & \multirow{2}{*}{\begin{tabular}{|c|}
$\begin{array}{c}\text { Duty } \\
\text { Cycle }\end{array}$ \\
$(\%)$ \\
\end{tabular}} & \multicolumn{2}{|c|}{ RPM } \\
\hline $\begin{array}{c}\text { High } \\
\text { (ms) }\end{array}$ & $\begin{array}{l}\text { Low } \\
\text { (ms) }\end{array}$ & & Actual & Selisih \\
\hline 10 & 90 & 10 & 230 & 110 \\
\hline 20 & 80 & 20 & 340 & 119 \\
\hline 30 & 70 & 30 & 459 & 120 \\
\hline 40 & 60 & 40 & 579 & 131 \\
\hline 50 & 50 & 50 & 710 & 110 \\
\hline 60 & 40 & 60 & 820 & 117 \\
\hline 70 & 30 & 70 & 937 & 123 \\
\hline 80 & 20 & 80 & 1060 & 150 \\
\hline 90 & 10 & 90 & 1210 & 195 \\
\hline 100 & 0 & 100 & 1405 & - \\
\hline \multicolumn{4}{|c|}{ Kenaikan RPM $/ 10 \%$ duty cycle } & 131 \\
\hline
\end{tabular}

Dari tabel 2 terlihat bahwa setiap kenaikan duty cycle sebesar $10 \%$ mengakibatkan kenaikan sebesar 131 RPM.

Uji momen inersia adalah untuk menguji seberapa jauh stator motor DC dapat ditahan oleh magnet permanen. Uji coba momen inersia dilakukan dengan cara memberikan pulsa PWM hanya dalam satu periode waktu.

Pada tabel 3 diperlihatkan hasil ujicoba momen inersia motor DC (3 kali pengukuran).

Tabel 3. Ujicoba momen inersia motor DC (3 kali pengukuran)

\begin{tabular}{|c|c|c|c|c|c|}
\hline \multicolumn{7}{|c|}{ Motor DC } \\
\hline \multicolumn{2}{|c|}{ Pulse } & $\begin{array}{c}\text { Duty } \\
\text { Cycle }\end{array}$ & \multicolumn{3}{|c|}{$\begin{array}{c}\text { Sudut } \\
\text { Simpangan } \\
\text { (Derajat) }\end{array}$} \\
\hline $\begin{array}{c}\text { High } \\
\text { (ms) }\end{array}$ & $\begin{array}{c}\text { Low } \\
\text { (ms) }\end{array}$ & $\mathbf{( \% )}$ & $\mathbf{1}$ & $\mathbf{2}$ & $\mathbf{3}$ \\
\hline 10 & 90 & 10 & TB & TB & TB \\
\hline 20 & 80 & 20 & TB & TB & TB \\
\hline 30 & 70 & 30 & 5 & 5 & 5 \\
\hline 40 & 60 & 40 & 10 & 15 & 20 \\
\hline 50 & 50 & 50 & 25 & 30 & 35 \\
\hline 60 & 40 & 60 & 40 & 45 & 45 \\
\hline 70 & 30 & 70 & 80 & 70 & 65 \\
\hline 80 & 20 & 80 & 110 & 125 & 140 \\
\hline 90 & 10 & 90 & 150 & 170 & 160 \\
\hline
\end{tabular}

$\mathrm{TB}=$ tidak bergerak
Dari tabel 3 terlihat bahwa duty cycle $30 \%$ adalah duty cycle terkecil untuk menggerakan rotor motor DC. Pada posisi ini tidak ada momen inersia karena rotor langsung ditahan oleh permanen magnet.

Apabila duty cycle ditingkatkan sebesar 10\% dari semula maka error sudut simpangan semakin besar (terjadi peningkatan momen inersia), sehingga motor DC tidak bisa diterapkan pada mekatronika dengan gerakan sudut persisi.

\section{Pengujian Motor Stepper}

Pengujian dilakukan pada motor stepper unipolar dengan resistansi $25 \Omega$ tiap komutator dengan rotasi 1.8 derajat/step. Pada tabel 4 diperlihatkan hasil pengukuran arus dan tegangan ditiap komutator motor stepper (PWM kontinyu)

Tabel 4. Hasil ukur arus dan tegangan komutator motor stepper (PWM kontinyu)

\begin{tabular}{|c|c|c|c|c|c|c|c|}
\hline \multicolumn{9}{|c|}{ FULL STEP } \\
\hline \multirow{2}{*}{ Step } & Pulse & S3 & S2 & S1 & S0 & $\begin{array}{c}\text { I } \\
\text { (mA) })\end{array}$ & $\begin{array}{c}\text { V } \\
\text { (Volt) }\end{array}$ \\
\hline \multirow{4}{*}{$\begin{array}{c}\text { Putar } \\
\text { Kiri }\end{array}$} & 1 & 0 & 0 & 0 & $\mathbf{l}$ & 210 & 4.75 \\
\cline { 2 - 8 } & 2 & 0 & 0 & $\mathbf{l}$ & 0 & 205 & 4.75 \\
\cline { 2 - 8 } & 3 & 0 & $\mathbf{1}$ & 0 & 0 & 215 & 4.75 \\
\cline { 2 - 8 } & 4 & $\mathbf{l}$ & 0 & 0 & 0 & 205 & 4.75 \\
\hline \multirow{4}{*}{$\begin{array}{c}\text { Putar } \\
\text { Kanan }\end{array}$} & 1 & $\mathbf{l}$ & 0 & 0 & 0 & 205 & 4.75 \\
\cline { 2 - 8 } & 2 & 0 & $\mathbf{l}$ & 0 & 0 & 215 & 4.75 \\
\cline { 2 - 8 } & 3 & 0 & 0 & $\mathbf{l}$ & 0 & 205 & 4.75 \\
\cline { 2 - 8 } & 4 & 0 & 0 & 0 & $\mathbf{l}$ & 210 & 4.75 \\
\hline
\end{tabular}

sesuai tabel 4, tegangan jepit antar komutator motor stepper adalah $4.75 \mathrm{~V}$ atau drop sebesar $0.25 \mathrm{~V}$, kejadian ini disebabkan karena terjadi perubahan impedansi pada saat motor diberi daya pada variasi frekuensi pulse step.

Tabel 5 diperlihatkan hasil pengukuran kecepatan putar rotate per minute (RPM) dengan variasi duty cycle. Kecepatan rotasi motor stepper diukur menggunakan laser tachometer pada PWM kontinyu 
Tabel 5. Hasil ukur kecepatan putar (RPM) pada variasi duty cycle (PWM Kontinyu)

\begin{tabular}{|c|c|c|c|c|}
\hline \multicolumn{5}{|c|}{ FULL STEP } \\
\cline { 1 - 1 } \multicolumn{2}{|c|}{ Pulse } & $\begin{array}{c}\text { Duty } \\
\text { Cycle }\end{array}$ & \multirow{2}{*}{ RPM } & RPM \\
\cline { 3 - 4 } $\begin{array}{c}\text { High } \\
\text { (ms) }\end{array}$ & $\begin{array}{c}\text { Low } \\
(\mathbf{m s})\end{array}$ & $(\%)$ & & Selisih \\
\hline 10 & 90 & 10 & 61 & 22 \\
\hline 20 & 80 & 20 & 83 & 22 \\
\hline 30 & 70 & 30 & 102 & 18 \\
\hline 40 & 60 & 40 & 120 & 18 \\
\hline 50 & 50 & 50 & 138 & 21 \\
\hline 60 & 40 & 60 & 157 & 19 \\
\hline 70 & 30 & 70 & 179 & 22 \\
\hline 80 & 20 & 80 & 201 & 22 \\
\hline 90 & 10 & 90 & 222 & 21 \\
\hline & \multicolumn{5}{|c}{ Rata-rata } & 20.66 \\
\hline
\end{tabular}

Pada tabel 5, setiap kenaikan duty cycle sebesar $10 \%$ mengakibatkan penurunan kecepatan (RPM) sebesar 20.66 atau dibulatkan sebesar 21. $10 \mathrm{~ms}$ adalah nilai terkecil dimana komutator mampu menimbulkan magnet, apabila diturunkan dari nilai $10 \mathrm{~ms}$ maka hanya akan terjadi isolasi (dengung) saja tanpa ada pergerakan motor sama sekali. Duty cycle sebesar $10 \%$ memberikan kecepatan maksimum pada motor stepper.

\section{Pengujian Motor Servo}

Sinyal PWM diijeksikan pada pin control motor servo pada lebar pulsa $1 \mathrm{~ms}, 1.5 \mathrm{~ms}$ dan 2 ms dalam perioda konstan $20 \mathrm{~ms}$. Pada tabel 6 diperlihatkan duty cycle arah putar dan sudut simpang motor servo (10 pulsa PWM)

Tabel 6 duty cycle arah putar dan sudut simpang motor servo (10 pulsa PWM)

\begin{tabular}{|c|c|c|c|c|}
\hline \multicolumn{5}{|c|}{10 pulsa PWM } \\
\hline \multicolumn{2}{|c|}{ Pulse } & \multirow{2}{*}{$\begin{array}{l}\text { Duty } \\
\text { Cycle }\end{array}$} & \multirow{2}{*}{$\begin{array}{l}\text { Arah } \\
\text { Putar }\end{array}$} & \multirow{2}{*}{$\begin{array}{c}\begin{array}{c}\text { Sudut } \\
\text { Simpang }\end{array} \\
\text { (Derajat) }\end{array}$} \\
\hline $\begin{array}{l}\text { High } \\
\text { (ms) }\end{array}$ & $\begin{array}{l}\text { Low } \\
\text { (ms) }\end{array}$ & & & \\
\hline 1.5 & 18.5 & 1.5 & Tahan & - \\
\hline 1 & 19 & 1 & Kiri & 4.9 \\
\hline 2 & 18 & 2 & Kanan & 4.2 \\
\hline \multicolumn{4}{|c|}{ Sudut Simpang (derajat) } & 0.7 \\
\hline
\end{tabular}

Dari tabel 6 diperlihatkan bahwa terjadi sudut simpang antara putar kiri dan putar kanan sebesar 0.7 derajat. Penyimpangan ini terjadi karena terjadi perbedaan yang signifikan duty cycle (2 kali atau $1 / 2$ kali) antara satu dengan yang lainnya. Sudut simpang ini tidak bisa diperbaiki karena decoder yang ada dalam motor servo hanya mengenal total perioda sebesar $20 \mathrm{~ms}$.

\section{KESIMPULAN}

Dari hasil eksperimen dan penempatan prototipe dapat disimpulkan sebagai berikut:

a. Pada pengendalian motor DC. Dengan PWM kontinyu terlihat bahwa setiap kenaikan duty cycle sebesar $10 \%$ mengakibatkan kenaikan sebesar 131 RPM. Uji momen inersia adalah untuk menguji seberapa jauh stator motor DC dapat ditahan oleh magnet permanen. Pada pengujian momen inersia (1 pulse PWM) terlihat bahwa duty cycle $30 \%$ adalah duty cycle terkecil untuk menggerakan rotor motor DC. Pada posisi ini tidak ada momen inersia karena rotor langsung ditahan oleh permanen magnet. Apabila duty cycle ditingkatkan sebesar $10 \%$ dari semula maka error sudut simpangan semakin besar (terjadi peningkatan momen inersia), sehingga motor DC tidak bisa diterapkan pada mekatronika dengan gerakan sudut persisi.

b. Pada pengendalian motor stepper. Ditunjukan bahwa tegangan jepit antar komutator motor stepper adalah $4.75 \mathrm{~V}$ atau drop sebesar $0.25 \mathrm{~V}$, kejadian ini disebabkan karena terjadi perubahan impedansi pada saat motor diberi daya. Setiap kenaikan duty cycle sebesar $10 \%$ mengakibatkan penurunan kecepatan (RPM) sebesar 21. 10ms adalah nilai terkecil dimana komutator mampu menimbulkan magnet, apabila diturunkan dari nilai $10 \mathrm{~ms}$ maka hanya akan terjadi isolasi (dengung) saja tanpa ada pergerakan motor sama sekali. Duty cycle sebesar $10 \%$ (high $10 \mathrm{~ms}$ dan low $90 \mathrm{~ms}$ ) memberikan kecepatan maksimum pada motor stepper.

c. Pada pengendalian motor servo. Ditunjukan bahwa terjadi sudut simpang antara putar kiri dan putar kanan sebesar 0.7 derajat. Penyimpangan ini terjadi karena terjadi perbedaan yang signifikan duty cycle (2 kali atau 1/2 kali) antara satu dengan yang lainnya. Sudut simpang ini 
sulit untuk diperbaiki karena decoder yang ada dalam motor servo hanya mengenal total perioda sebesar $20 \mathrm{~ms}$. Sehingga bisa dikatakan pengukuran sudut dengan motor servo adalah tidak persisi.

\section{UCAPAN TERIMA KASIH}

Penelitian ini didukung Oleh Prodi Elektro Fakultas Sains dan Teknologi Universitas Al Azhar Indonesia, didanai oleh Research Grant 2015-2016 LP2M UAI

\section{DAFTAR ACUAN/PUSTAKA}

[1] DC

Motor

Driver, http://www.alldatasheets. .com/L298.html, (Diakses pada 24 Sept 2015)

[2] http://www.pbclinear.com/Download/Data Sheet/Stepper-Motor-Support Document.pdf, (Diakses pada 25 Sept 2015).

[3] Labcentre Electronic, Proteus design suite, product guide. Website retrieved from .http//www.labcenter.com, (Diakses pada 2 Sept 2015)
[4] Lam Zi-Yi; Wong Sew-Kin.The design of DC motor driver for solar tracking applications.10th IEEE International Conference on Semiconductor Electronics (ICSE), 2012.

[5] L. Xiaosheng, W. Yuqiang, H. Nantian \& H. Yue, The Networked Virtual Test System for Servo Motor and Drive Based on LabVIEW, Proceeding IEEE 7th international conference on Power Electronics and Motion Control, 1-5, 2012

[6] N. Greenough; C. C. Kung, A new highefficiency stepper motor driver for old technology stepper motor,IEEE 25th Symposium on Fusion Engineering (SOFE), 2013.

[7] S. Sharp, A. Wicks, A. Ordys \& G. Collier, Modelling of a Pan and Tilt Servo System, Proceeding of IEEE International Conference on Control, 1-5, 2012

[8] TowerPro SG-5010 Servo Specifications and Reviews, http://www.servodatabase.com/servo /servo/towerpro/sg-5010, (Diakses pada 25 September 2015).

[9] Western Engineering Mechatronic Systems Engineering, http://www.eng.uwo.ca/under_graduate/pr ograms/Mechatronic.html.2015. (Diakses pada 2 Sept 2015) 